\title{
La noción del paisaje en el alumnado de Educación Primaria: un análisis de su representación
}

\author{
Ramón Martínez-Medina \\ Covadonga Ávila-Marín \\ Universidad de Córdoba. Departamento de Didáctica de las Ciencias Sociales \\ y Experimentales \\ rmartinez@uco.es \\ m02avmac@uco.es
}

\section{Resumen}

Este trabajo de investigación quiere poner de relieve la importancia del estudio del paisaje en Educación Primaria. El conocimiento y la relación con el paisaje mejoran la educación del ser humano y la adquisición de unos valores necesarios para la vida en sociedad. Por ello, se debe comenzar educando desde el aula, con los más pequeños, para que crezcan en un continuo conocimiento y contacto con el medio ambiente y el paisaje. El objetivo de la investigación es conocer cuáles son las representaciones que realiza el alumnado de Educación Primaria sobre el paisaje. La metodología empleada, de doble vía, cualitativa y cuantitativa, se ha basado en el análisis de los dibujos realizados por alumnado de cada ciclo de esta etapa educativa.

Palabras clave: paisaje; educación geográfica; Educación Primaria

Resum. La noció del paisatge en l'alumnat d'Educació Primària: una anàlisi de la seva representació

Aquest treball de recerca vol posar en relleu la importància de l'estudi del paisatge en Educació Primària. El coneixement i la relació amb el paisatge milloren l'educació de l'ésser humà i l'adquisició d'uns valors necessaris per a la vida en societat. Per això, s'ha de començar educant des de l'aula, amb els més petits, perquè creixin en un continu coneixement $\mathrm{i}$ contacte amb el medi ambient i el paisatge. L’objectiu de la investigació és conèixer quines són les representacions que realitza l'alumnat d'Educació Primària sobre el paisatge. La metodologia utilitzada, de doble via, qualitativa i quantitativa, s'ha basat en l'anàlisi dels dibuixos fets per alumnat de cada cicle d'aquesta etapa educativa.

Paraules clau: paisatge; educació geogràfica; Educació Primària 
Résumé. La notion du paysage chez les élèves de l'école primaire: analyse de leur représentation

Ce travail de recherche vise à mettre en évidence l'importance de l'étude du paysage dans l'enseignement primaire. La connaissance et la relation avec le paysage améliore l'éducation de l'être humain et l'acquisition des valeurs nécessaires à la vie en société. Par conséquent, nous devons commencer par éduquer à partir de la salle de classe, avec les plus jeunes, afin qu'ils grandissent dans une connaissance continue et un contact avec l'environnement et le paysage. L'objectif de la recherche est de savoir quelles sont les représentations que se font les élèves de l'enseignement primaire sur le paysage. La méthodologie duelle, à la fois qualitative et quantitative, s'est basée sur l'analyse des dessins réalisés par les étudiants de chaque cycle de cette étape de l'enseignement.

Mots-clés: paysage; éducation géographique; éducation primaire

\begin{abstract}
An analysis of landscape representation among primary school students
This research underscores the importance of studying the landscape in primary education. Knowledge about the landscape and people's relationship with it improve human beings' education and promote the acquisition of essential values for social life. Therefore, landscape education must begin in the classroom in the early years so that students grow through their knowledge of and contact with the environment and the landscape. The objective of the research is to determine how primary education students represent the landscape. To this end, a qualitative and quantitative methodology has been used to analyze students' drawings in each primary education cycle.
\end{abstract}

Keywords: landscape; geography education; primary education

\author{
Sumario \\ 1. Introducción 4. Conclusiones \\ 2. Objetivo y metodología Referencias bibliográficas
}

3. Análisis y resultados

\title{
1. Introducción
}

El paisaje es un concepto que vincula el entorno físico con las sociedades humanas. Al ser un producto elaborado a lo largo del tiempo, a menudo miles de años, ha sufrido muchos cambios. Por tanto, los paisajes implican interacciones entre pasado y presente, y dan un sentido de identidad espacial a escala individual, local, regional o nacional (Kärkkäinen et al., 2017). A veces, tales cambios son lentos y sutiles; en otros casos, dramáticos y rápidos (Antrop, 2000, 2006), pero siempre están cargados de intencionalidad. El paisaje se puede considerar como un escenario que refleja las diferentes expresiones e intercambios de valores y significados propios de los elementos que lo componen. La formación del alumnado en esta dimensión pone su foco en el aporte de unos procedimientos e instrumentos para poder descodificar los valores recogidos en el medio (Busquets, 2010), teniendo en cuenta que en 
toda interpretación hay que apreciar todas las variables y connotaciones que definen cada proceso comunicativo.

Durante la etapa de Educación Primaria, el alumnado adquiere un saber reflexivo sobre las prácticas comunicativas para adaptarse a la sociedad del siglo XXI, y así afrontar los desafíos e incertidumbres de esta. Por esta razón, la comunicación es trabajada mediante un enfoque interdisciplinar en todas las áreas, con el empleo del lenguaje como medio de comunicación y tratamiento de la información. Es decir, se pretende el desarrollo de la competencia en comunicación lingüística entendiéndola como el conjunto de conocimientos, destrezas y actitudes necesarios para el uso del lenguaje como instrumento de expresión que posibilita la experiencia humana partiendo de su realidad y pensamiento. De acuerdo con esta idea, Puyuelo y Rondal (2003) definen el lenguaje como todo instrumento de comunicación o código que permite expresar y percibir estados afectivos, ideas, necesidades y experiencias a través de un proceso activo de codificación, transmisión y descodificación. Desde esta perspectiva, el lenguaje plástico se concibe como la capacidad de los seres humanos para comunicar, representar y expresar la realidad de manera original a través de imágenes y signos gráficos. Por otra parte, se estructura en torno a dos ejes: la percepción (desarrollando capacidades sensoriales que ayudan a entender las manifestaciones artísticas) y la expresión de ideas y sentimientos a través de códigos y técnicas. Por ello, es necesario enseñar a los estudiantes a contemplar e interpretar imágenes para que sean capaces de aprender a mirar, analizar y comprender.

De igual modo, queremos relacionar esta temática con la importancia del conocimiento y la representación del medio más cercano al alumnado, ya que en contacto con él formarán sus primeros aprendizajes.

Teniendo en cuenta la contemplación de los valores estéticos del medio y su análisis para obtener información del pasado y, de este modo, poder analizar la realidad del presente, se entenderá por paisaje «cualquier parte del territorio tal como la percibe la población, cuyo carácter sea el resultado de la acción y la interacción de factores naturales y/o humanos» (Convenio Europeo del Paisaje, 2000: 2). Son muchas las relaciones establecidas entre sus elementos, que amplían la complejidad de su estudio en los diferentes ámbitos o disciplinas, como la geografía, la ecología o la antropología (Liceras, 2003: 19). Liceras determina los rasgos característicos del paisaje como espacio percibido, marco de vida, recurso, patrimonio, portador de semiología (espacio-tiempo), problema, valor de identidad de un colectivo, espacio estético o identificación ideológica (2003: 22-23). Así mismo, se entiende como un recurso educativo propio, en el que se incorporan los enfoques más tradiciones (basados en la percepción) con dimensiones más sociales (Busquets, 1996, 2011).

Este objeto de estudio hace referencia a un recurso educativo con múltiples potencialidades que debe trabajarse desde el entorno más cercano al niño (Bajo, 2001), y constituir un tema central en el proceso de enseñanza y aprendizaje de la geografía y la educación ambiental (Medley y Gramlich-Kaufman, 2001; Batllori y Serra, 2017; Siama et al., 2018). 
Es así como el paisaje se convierte en un potente comunicador cultural, ya que nos brinda información sobre las sociedades y su evolución en un marco espaciotemporal; así como de este geosistema y de la transformación de sus elementos bióticos y abióticos (Hermann, 1996; Loughland et al., 2002; Scott et al., 2009; Lambert y Morgan, 2010; Rickinson, 2010). Se puede afirmar que existe un «lenguaje del lugar», en el que ocurren transmisiones de mensajes que nos ofrecen oportunidades comunicativas (incluyendo estudios de percepción o discurso) con la finalidad de interpretar el espacio y dotarlo de un tratamiento como sistema de comunicación en el que se considera el entorno como ente mediador y como sistema de comunicación físico y social (Mela, 1994).

Como pone de manifiesto Giner de los Ríos (Liceras, 2013: 85), entender el paisaje es abrirse a un mundo de significados, de valores y cuidados de muy variada índole, cuya comprensión ayuda sustancialmente a mejorar la educación del hombre. El contacto con el paisaje permite educar la inteligencia y, al tiempo, la sensibilidad y la imaginación, y también incrementa las capacidades éticas y estéticas de la persona.

Los dibujos ofrecen grandes potencialidades educativas, como permitir poner de manifiesto diversas maneras de leer un paisaje según los diferentes bagajes culturales del alumnado. Permiten comparaciones entre sí o con fotografías de los lugares representados (hechas por ellos mismos o extraídas de libros o internet). Durante una salida el campo, el alumnado también puede hacer bocetos del paisaje y compararlos con los que se han realizado antes de la salida, en busca de semejanzas, diferencias y otros detalles. Estas actividades permiten reflexionar sobre los diferentes elementos del paisaje y conocerlos mejor (Nogué et al., 2011: 179).

Las representaciones del paisaje nos informan sobre los modelos del alumnado, y existen pruebas considerables de que pueden ser herramientas útiles para conocer y evaluar los niveles de comprensión de fenómenos naturales, y para identificar sus puntos de vista científicos (Barraza, 1999; Dove et al., 1999; Ehrlén, 2009; Kalvaitis y Monhardt, 2012; Lebaza et al., 2017; Kärkkäinen et al., 2017).

Por ello, hay que distinguir entre imágenes que ilustran e ilustraciones que visualizan, y considerar las representaciones de los infantes como ilustraciones simbólicas que reflejan las construcciones intelectuales o conocimientos de los discentes en la materia y la visualización del paisaje como percepciones que nos ilustran la evolución del espacio a lo largo del tiempo. En otras palabras, el dibujo del niño constituye una imagen didáctica o un esquema, ya que presenta los siguientes rasgos: una abstracción de lo esencial, una concentración de información sin variar su esencia, una lógica gestáltica en la organización de los elementos de la imagen y una actitud de normatividad para facilitar la percepción del lenguaje icónico. Por consiguiente, su poder didáctico contribuye a hacer visibles cosas que por su naturaleza no lo son y a hacer de estas algo imaginable y comprensible (Costa y Moles, 1991: 58).

Busquets (1977) señala que una imagen tiene una doble función, ya que es una representación visual de la realidad con imágenes mentales basada en los 
contornos para expresar una idea. Por tanto, una imagen «presenta» (enseña o muestra) y «representa» (simboliza una idea o un conocimiento).

Son muchos los académicos que a lo largo de las últimas décadas han realizado estudios de campo sobre el dibujo infantil. Entre ellos, destacan autores como Arnheim (1954), Widlhöcher (1982), Lowenfeld (1947, 1958), o la obra que comparte con Lambert (1980). Otras más recientes y notables pueden ser las aportaciones de Philipe Wallon et al. (1992) y la de Donna Darling Kelly (2004), que realiza un recorrido por el dibujo infantil a lo largo de la historia. Parte del hecho de que las ideas y los posicionamientos formulados en estas investigaciones se refieren principalmente a fenómenos que podría parecer que no están actualizados. Sin embargo, estos posicionamientos conservan su importancia y siguen aportando un enorme valor cognitivo a los fenómenos estudiados (Wiśniewska, 2017).

Para poder analizar las representaciones que los escolares realizan sobre el paisaje, hay que tener en cuenta las características particulares de su desarrollo creativo (Lowenfeld y Lambert, 1980):

- Fase preesquemática o de la figuración (4-7 años): el niño/a crea formas conscientemente como resultado de la evolución de un conjunto de líneas para la creación de una representación definida. Para ello, traslada gráficamente las imágenes almacenadas en su memoria, por adición. En esta etapa, se trabajan algunas técnicas de color y modelado, y se dibuja con la pretensión de representar aquello que es percibido a través de los sentidos. Las representaciones del espacio estarán sujetas a diversos aspectos, como la cultura o los valores de la sociedad en la que viven. Sin embargo, a través de la representación de aquello que le rodea, el niño localizará los objetos arriba o abajo según los comprenda, por lo que sería interesante observar el espacio percibido por el pequeño/a.

- Fase esquemática (7-9 años): el alumnado sigue unos modelos que son los que va a reproducir en sus dibujos, para expresar sus emociones y sentimientos. Las figuras se realizan por contorno y se tienen en cuenta los rasgos propios de la figura humana (ojos, cejas, nariz, pelo). El principal descubrimiento en esta etapa es la existencia de un orden en las relaciones espaciales de todos los objetos de su entorno. Así, realizan dibujos con vista abatida en los que ubican los elementos sobre una línea base (que simboliza la superficie del terreno).

- Fase realista (9-12 años): las representaciones se dirigen hacia un planteamiento donde el realismo visual adquiere más relevancia. El niño/a presta más atención al cuidado de las formas y proporciones. Aumenta su capacidad analítica y perceptiva, y se introduce en el claroscuro. Respecto al significado del espacio, se aleja de la representación de lo concreto para manejar conceptos abstractos, y es capaz de distribuir varias imágenes sobre este.

- Fase pseudonaturalista (12-14 años): les interesa la ilusión de profundidad, con hincapié en el claroscuro y en la composición. Por otro lado, los adolescentes son más críticos con sus obras, manifiestan sus intereses y expresan sus ideas 
a través del dibujo. Estos autores exponen que uno de los grandes descubrimientos en esta edad es la reducción del tamaño de los objetos y la apreciación de las cualidades tridimensionales del espacio y las diferentes perspectivas.

El análisis de las representaciones del alumnado no es posible sin la contextualización curricular de este concepto. Son diversos los trabajos publicados en los últimos años sobre el papel de la enseñanza del paisaje en los currículos oficiales adaptados a la normativa educativa vigente - Ley Orgánica para la Mejora de la Calidad Educativa (LOMCE) - . Algunos hacen referencia al abordaje del paisaje en Educación Infantil (Martínez y García-Moris, 2014) y en Educación Primaria (Martínez et al., 2018), y también existen trabajos relacionados con el paisaje en Educación Secundaria (Casas y Erneta, 2015; Casas et al., 2017). En ellos, se pone de manifiesto que en las etapas educativas iniciales existe un excesivo protagonismo de los paisajes naturales frente a la enseñanza de los paisajes humanizados, donde se desenvuelve la mayor parte del alumnado de Educación Primaria en España, lo que puede suponer un problema a la hora de conocer e interpretar el espacio cercano en el que viven (Martínez y Ávila, 2014; Martínez y Arrebola, 2016; Martínez et al., 2018).

El Real Decreto 126/2014 de 28 de febrero (en vigor) aborda el estudio del paisaje en el segundo bloque del Área de Ciencias Sociales (El mundo en el que vivimos). En este último, los contenidos establecidos para su enseñanza son:

- La diversidad geográfica de los paisajes de España: relieve e hidrografía.

- La diversidad geográfica de los paisajes en Europa: relieve, climas e hidrografía.

- La intervención humana en el medio.

Para concluir este apartado, es necesaria la mención a la legislación andaluza, comunidad autónoma en la que se ha llevado a cabo esta investigación. En la Orden del 17 de marzo de 2015, por la que se desarrolla el currículo de Educación Primaria en Andalucía, se presta especial atención al paisaje, la intervención humana en el medio y los paisajes andaluces. Para ello, se velará por una metodología de enseñanza basada en el análisis y la interpretación de la realidad más cercana, con la idea de descubrir «la riqueza de la diversidad geográfica y cultural para aprender a valorarla y cuidarla».

\section{Objetivo y metodología}

El objetivo principal de este estudio es conocer cuáles son las nociones del alumnado referentes al paisaje y sus elementos. En este caso concreto, abordar las representaciones del paisaje que tiene el alumnado de Educación Primaria.

La muestra está formada por 203 estudiantes de Educación Primaria. Tras descartar los casos incompletos o con falta de información, se han tenido en cuenta un total de 165 casos. En cuanto al sexo, 87 son niñas $(52,72 \%)$ y 78 niños $(47,27 \%)$, con edades comprendidas entre los 6 y los 12 años, y distribuidos en los tres ciclos de Educación Primaria durante el curso 2017-2018. El alumnado de la muestra pertenece a varios centros educativos de titularidad 
Tabla 1. Composición de la muestra

\begin{tabular}{lcccc}
\hline Ciclo & Niños & Niñas & Total & $\%$ \\
\hline Primero & 37 & 31 & 68 & $41,21 \%$ \\
Segundo & 23 & 38 & 61 & $36,96 \%$ \\
Tercero & 18 & 18 & 36 & $21,81 \%$ \\
\hline Total & 78 & 87 & 165 & $100 \%$ \\
\hline
\end{tabular}

Fuente: elaboración propia.

pública de la zona norte de la ciudad de Sevilla, situados en barrios de clase media y media-baja. La selección de centros se realizó mediante un muestreo intencional no probabilístico. La representación de los diferentes ciclos es variada, con la participación sobre todo de alumnado del primer ciclo $(41,21 \%)$ y del segundo $(36,96 \%)$ de Educación Primaria, mientras que el tercer ciclo $(21,81 \%)$ cuenta con menor representación (tabla 1).

Se lleva a cabo un diseño mixto de investigación, ya que supone la recopilación y el análisis de datos desde ambos enfoques en un mismo estudio (Creswell y Plano-Clark, 2007). Desde el punto de vista cualitativo, se registra información sobre las interpretaciones y representaciones gráficas de los estudiantes. Como instrumento de recogida de información, se ha diseñado una parrilla de análisis en la que se reflejan apreciaciones sobre las representaciones realizadas. La parrilla se compone de tres categorías diferentes.

La primera pretende presentar los datos identificados generales de cada alumno, específicamente el sexo, la edad y el curso en el que se encuentra. En la segunda categoría de tipo cuantitativo, se distinguen inicialmente los tipos de paisajes: primero, entre paisajes naturales y humanizados, y dentro de estos últimos, entre rurales y urbanos. También se cuantifican los elementos de cada tipo de paisaje representado (montañas, ríos, valle, edificios, cultivos, arboles, etcétera). Este enfoque cuantitativo aportó datos concretos que fueron analizados estadísticamente para construir una visión global que llevaba implícito dar sentido a la información recogida, con el propósito de establecer una valoración final. La última categoría tiene un carácter cualitativo, donde se desarrolla una interpretación global del dibujo.

Las representaciones fueron realizadas de forma voluntaria en el aula, durante un tiempo máximo de 30 minutos, a modo de evaluación inicial antes de la impartición de las unidades didácticas sobre paisaje, en los cursos donde las hay. En los que no, se le pidió al alumnado que realizara un dibujo libre de un paisaje. No fue preciso llevar a cabo un protocolo para controlar la heterogeneidad a la hora de establecer las directrices en la realización de la actividad, ya que, por un lado, se trataba de un dibujo libre, con el objetivo de valorar qué tipo de paisaje se dibuja, y por otro, porque las directrices las dieron directamente los investigadores del proyecto a los discentes, no el profesorado de Educación Primaria.

Con relación al procedimiento seguido, organizamos las tareas teniendo en cuenta las siguientes dimensiones: el tipo de paisaje dibujado por el discente, 
los elementos representados, si reflejan un paisaje cotidiano y el desarrollo del trazado del dibujo. De este modo, se pretende conocer la percepción que tienen los discentes sobre el paisaje, si conciben el paisaje únicamente como medio natural o si, por el contrario, son capaces de apreciar y valorar los elementos de su medio más cercano; teniendo en cuenta que las modificaciones e intervenciones del hombre en los ecosistemas forman parte del paisaje humanizado (rural o urbano).

El proceso de descodificación seguido alude a la sucesión o fases planteadas por Bertin (1991, citado en Costa y Moles, 1991: 171):

Figura 1. Comunicación gráfica eficaz

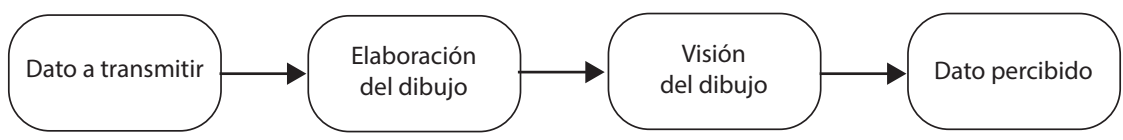

Fuente: Bertín (1991: 171).

Conviene aclarar que la información está estructurada en tres ciclos, de acuerdo con la organización de esta etapa educativa en la Comunidad Autónoma de Andalucía, teniendo en cuenta el nivel madurativo de cada grupo: primer ciclo $\left(1 . .^{\circ}\right.$ y $\left.2 .^{\circ}\right)$, segundo ciclo $\left(3 .^{\circ}\right.$ y $\left.4 . .^{\circ}\right)$ y tercer ciclo $\left(5 . .^{\circ}\right.$ y $\left.6 .^{\circ}\right)$ de Educación Primaria.

\section{Análisis y resultados}

Tras el análisis de la información extraída, procedemos a la interpretación y la exposición de los resultados obtenidos.

En cuanto a las representaciones del paisaje en el primer ciclo de Educación Primaria, se puede observar que el alumnado mayoritariamente se ha decantado por los paisajes humanizados $(60,29 \%)$, frente a los de tipo natural $(39,71 \%)$. Por cursos, esta diferencia es mayor, pues son los de primero los que han optado por los paisajes humanizados $(76,47 \%)$, frente a los de segundo, en los que existe un reparto más homogéneo entre ambos tipos (tabla 2).

El alumnado de primero diferencia claramente los dos tipos de paisaje principales: paisaje natural y humanizado (en el que encontramos dos variantes: el

Tabla 2. Representaciones del paisaje en primer ciclo

\begin{tabular}{lccccccc}
\hline & \multicolumn{9}{c}{ Tipo de paisaje } & & \\
\cline { 2 - 5 } \multicolumn{1}{c}{ Curso } & Natural & $\%$ & Humanizado & $\%$ & & Total & $\%$ \\
\hline Primero & 8 & 23,53 & 26 & 76,47 & 34 & 100,00 \\
Segundo & 19 & 55,88 & 15 & 44,12 & 34 & 100,00 \\
Total ciclo & 27 & 39,71 & 41 & 60,29 & 68 & 100,00 \\
\hline
\end{tabular}

Fuente: elaboración propia. 
Tabla 3. Representaciones del paisaje humanizado en primer ciclo

\begin{tabular}{lccccccc}
\hline & \multicolumn{5}{c}{ Paisaje humanizado } & & \\
\cline { 2 - 5 } \multicolumn{1}{c}{ Curso } & Rural & $\%$ & Urbano & $\%$ & & Total & $\%$ \\
\hline Primero & 8 & 30,77 & 18 & 69,23 & & 26 & 100,00 \\
Segundo & 7 & 46,67 & 8 & 53,33 & & 15 & 100,00 \\
Total ciclo & 12 & 29,27 & 29 & 70,73 & & 41 & 100,00 \\
\hline
\end{tabular}

Fuente: elaboración propia.

paisaje urbano y el rural). Respecto a los datos obtenidos, 18 discentes se decantaron por la representación del paisaje urbano, 8 por el paisaje rural y otros 8 por el paisaje natural (tabla 3). Es curioso observar que todos los paisajes hacen alusión al día y no a la noche, y en la mayoría de los casos con el dibujo del sol como elemento significativo. Casi todos los escolares aprecian los valores estéticos del paisaje e intentan reflejar la realidad de lo que perciben. Para ello, utilizan los tamaños, las proporciones y los colores adecuados a cada uno de los elementos.

Respecto a la etapa de su desarrollo creativo, encontramos una amplia diversidad de variables: desde un gran grupo de discentes con habilidades propias de la etapa esquemática (donde es característica la superposición de los objetos) hasta otros que todavía permanecen en el garabateo o en la etapa de preesquemática (donde es peculiar la formación de figuras mediante la adición).

En los dibujos del paisaje natural, son predominantes algunos elementos como el agua (en el mar o en los ríos), las montañas, el suelo o la tierra, la vegetación con flores y los árboles y la fauna, con animales como peces, mariposas y seres humanos (y se representa el propio alumno o alumna). Resultó curiosa y original la representación de un alumno que esbozó nuestro sistema solar como paisaje natural, explicando que su origen tiene lugar por fenómenos naturales (figura 2).

Por otro lado, muchos se decantaron por reflejar un espacio rural, con elementos bióticos y abióticos (las montañas, la vegetación, el cielo y el agua) y elementos antrópicos (las casas y los caminos). En el caso de los paisajes urbanos, apenas aparecen elementos naturales (se trazan solo objetos como el sol, las nubes o algún árbol), mientras que sí son característicos los edificios altos y los coches. La razón principal podría radicar en el barrio en el que vive el alumnado, en pleno núcleo de la ciudad de Sevilla. Por ello, podemos mencionar que representan paisajes cercanos al medio en el que viven o han visitado.

En segundo, existen notables diferencias respecto al curso anterior. Desciende la presencia de los paisajes humanizados frente a los naturales, aunque su proporción es más o menos similar: un $44,12 \%$ frente a un $55,80 \%$. Lo mismo que ocurre con los paisajes humanizados (paisajes rurales, 46,67\%; paisajes urbanos, 53,33\%) (tabla 3).

Entre los elementos naturales más significativos en estos dibujos, encontramos el sol, el cielo, la fauna (con una amplia diversidad de animales, como conejos, leones, pájaros o peces), el suelo, las montañas y el agua (ríos y mares), y destaca la presencia de algunos paisajes costeros. 
Figura 2. Representación del paisaje natural en $1{ }^{\circ}$ de Educación Primaria

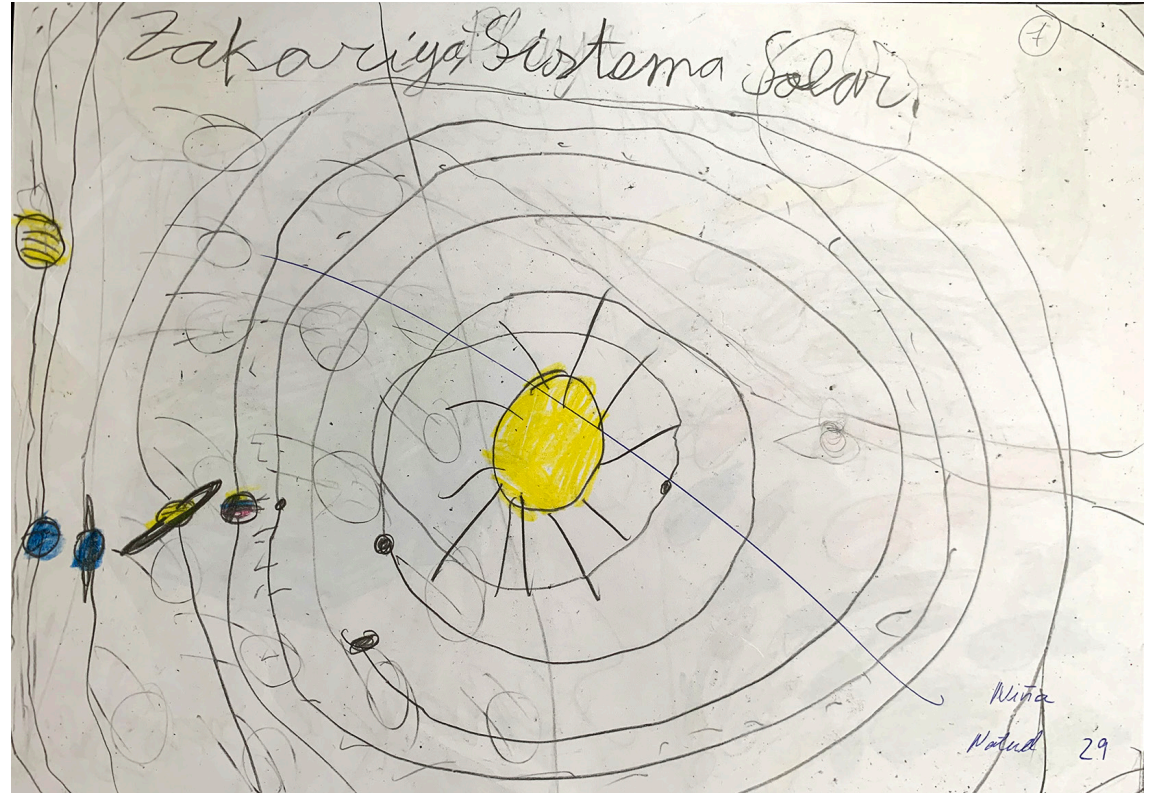

Fuente: elaborado por el alumnado participante en el estudio.

En la mayoría de los gráficos sobre el paisaje rural, existe un equilibrio entre los elementos naturales y los antrópicos, con el predominio de las casas, los pozos (figura 3), algún medio de transporte (coches o aviones), los árboles, las flores y los animales.

El paisaje urbano más representado hace mención del espacio más cercano al alumnado. Algunos estudiantes de origen magrebí se refieren a París, donde viven sus familias, y otros a la ciudad de Sevilla, donde residen, con paisajes como Isla Mágica.

Con relación a las propiedades y las características de los dibujos, ya en esta edad la mayoría sitúa los elementos sobre una línea base y dibuja objetos de menor tamaño para darle mayor percepción de fondo. Sin embargo, a diferencia del curso anterior, ninguno realiza superposiciones, aunque siga siendo una peculiaridad de la próxima etapa.

De este modo, acabamos con el primer ciclo, en el que existen considerables diferencias en la representación y la noción que tienen los alumnos sobre el paisaje. Destacan el primer curso, en el que una mayoría seleccionó el paisaje humanizado, y el segundo, donde se concibe el paisaje como medio natural.

Los resultados obtenidos en el segundo ciclo $\left(3 .^{\circ}\right.$ y $4 .^{\circ}$ de Educación Primaria) fueron muy diferentes. En tercero, un total de 28 alumnos representaron el paisaje natural $(87,50 \%)$, y en cuarto, el humanizado (12,50\%). Llama la atención la escasez de dibujos de paisajes urbanos. En cuarto, la situación 


\section{Figura 3. Representación del paisaje rural en $2 .^{\circ}$ de Educación Primaria}

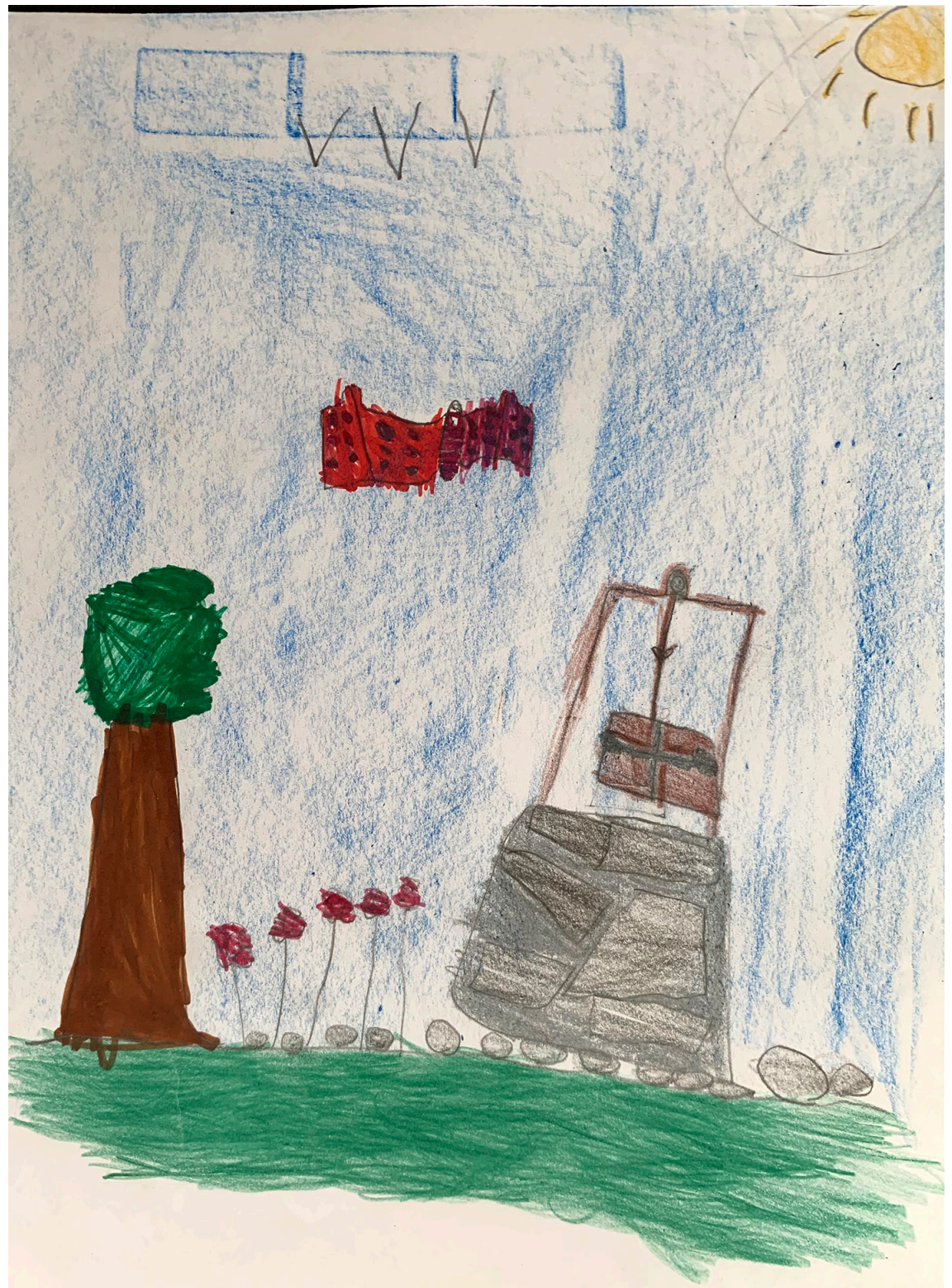

Fuente: elaborado por el alumnado participante en el estudio. 
Tabla 4. Representaciones del paisaje en segundo ciclo

\begin{tabular}{lccccccc}
\hline & \multicolumn{9}{c}{ Tipo de paisaje } & & \\
\cline { 2 - 5 } Curso & Natural & $\%$ & humanizado & $\%$ & & Total & $\%$ \\
\hline Tercero & 28 & 87,50 & 4 & 12,50 & & 32 & 100,00 \\
Cuarto & 25 & 86,21 & 4 & 13,79 & & 29 & 100,00 \\
Total ciclo & 53 & 86,89 & 8 & 13,11 & & 61 & 100,00 \\
\hline
\end{tabular}

Fuente: elaboración propia.

Tabla 5. Representaciones del paisaje humanizado en segundo ciclo

\begin{tabular}{lcccccc}
\hline & \multicolumn{7}{c}{ Paisaje humanizado } & & \\
\cline { 2 - 5 } Curso & Rural & $\%$ & Urbano & $\%$ & & Total \\
\hline Tercero & 3 & 75 & 1 & 25 & & $\%$ \\
Cuarto & 4 & 100 & 0 & 0 & 4 & 100 \\
Total ciclo & 7 & 87,5 & 1 & 12,5 & 8 & 100 \\
\hline
\end{tabular}

Fuente: elaboración propia.

fue muy parecida, con 25 gráficos del paisaje natural $(86,21 \%)$ y 4 también de paisaje humanizado $(13,79 \%)$, todos correspondientes a paisajes rurales (tabla 4 y tabla 5).

En este ciclo, entre los elementos del paisaje natural más característicos, encontramos ríos, animales, árboles, flores y montañas; y en uno destaca la presencia de la lluvia. Mientras que en la representación de los paisajes humanizados, en el paisaje rural resalta la casa como elemento antrópico. El caso más destacado es el de un dibujo de un paisaje rural en el que aparecen unas huertas y una iglesia (figura 4).

Para finalizar con este ciclo, vamos a describir brevemente los aspectos sobre su desarrollo en el dibujo. Conviene mencionar que el alumnado va colocando los elementos superpuestos, tiene en cuenta los rasgos de las figuras humanas o de los animales (dibuja los ojos, la nariz y el pelo) y utiliza los colores para expresar sus emociones.

Respecto a la realización de las representaciones del paisaje en el último ciclo, muchas pruebas quedaron en blanco, por lo que este ciclo es el que tiene menor representación en la muestra analizada. Los motivos pueden ser varios, desde la inexperiencia del alumnado para dibujar paisajes hasta la poca motivación de los discentes a participar en la investigación. Esta fue la principal razón por la que obtuvimos 30 representaciones de paisaje natural (22 en $5 .^{\circ}$ y 8 en $6 .^{\circ}$ ) y 6 de paisaje humanizado ( 4 en $5 .^{\circ}$ y 2 en $6 .^{\circ}$ ) (tabla 6 y tabla 7$)$.

Entre los dibujos analizados, es curioso observar que algunos paisajes hacen referencia a espacios humanizados con piscina y pistas de deporte, o a un medio natural donde encontramos elementos como volcanes o una tormenta. En muchos casos, sigue siendo característico el animismo en elementos como el sol, así como algunos aspectos propios de la etapa en la que se encuentran: 
Figura 4. Representación del paisaje rural en $4 .^{\circ}$ de Educación Primaria

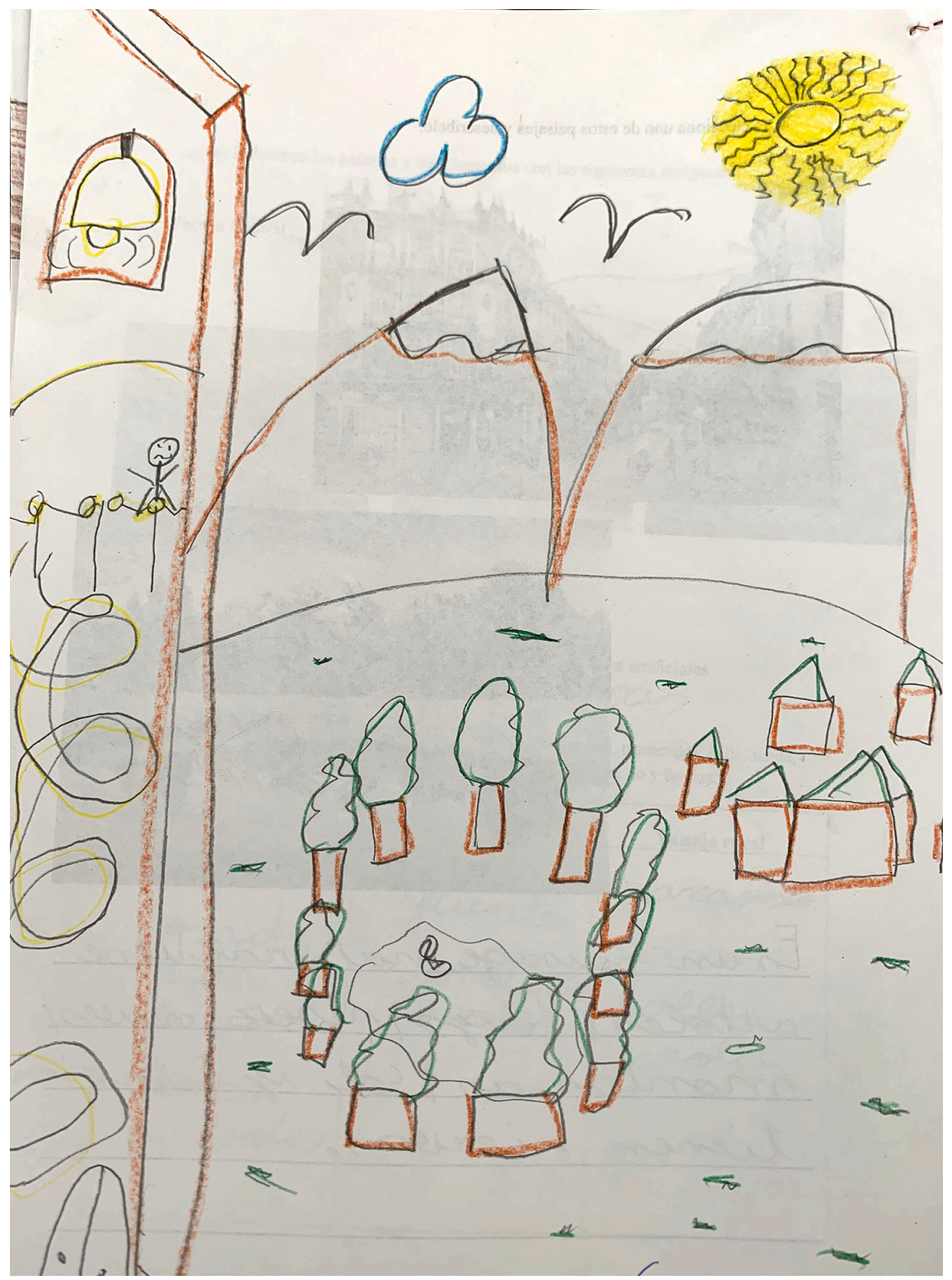

Fuente: elaborado por el alumnado participante en el estudio. 
Tabla 6. Representaciones del paisaje en tercer ciclo

\begin{tabular}{lccccccc}
\hline & \multicolumn{9}{c}{ Tipo de paisaje } & & \\
\cline { 2 - 5 } \multicolumn{1}{c}{ Curso } & Natural & $\%$ & Humanizado & $\%$ & & Total & $\%$ \\
\hline Quinto & 22 & 84,62 & 4 & 15,38 & & 26 & 100,00 \\
Sexto & 8 & 80,00 & 2 & 20,00 & & 10 & 100,00 \\
Total ciclo & 30 & 83,33 & 6 & 16,67 & 36 & 100,00 \\
\hline
\end{tabular}

Fuente: elaboración propia.

Tabla 7. Representaciones del paisaje humanizado en tercer ciclo

\begin{tabular}{|c|c|c|c|c|c|c|}
\hline \multirow[b]{2}{*}{ Curso } & \multicolumn{4}{|c|}{ Paisaje humanizado } & \multirow[b]{2}{*}{ Total } & \multirow[b]{2}{*}{$\%$} \\
\hline & Rural & $\%$ & Urbano & $\%$ & & \\
\hline Quinto & 1 & 25,00 & 3 & 75,00 & 4 & 100,00 \\
\hline Sexto & 2 & 100,00 & 0 & 0,00 & 2 & 100,00 \\
\hline Total ciclo & 3 & 50,00 & 3 & 50,00 & 6 & 100,00 \\
\hline
\end{tabular}

Fuente: elaboración propia.

el uso de la sombra, la proporción de los elementos y la representación de sus intereses y de objetos tridimensionales (figura 5).

Por el contrario, hemos comprobado que, conforme se avanza en los cursos educativos de esta etapa, van disminuyendo las representaciones de su paisaje cotidiano, el paisaje humanizado, y en este caso específico, el paisaje urbano, ya que no lo conciben como tal. Esto puede estar relacionado con el currículo preceptivo, en el que existe un predominio por la enseñanza de los paisajes naturales frente a los paisajes humanizados, como ya han puesto de manifiesto algunos trabajos que han analizado dicha cuestión (Martínez et al., 2018).

Para finalizar, cabe mencionar que la mayoría de los discentes no reconocen los distintos tipos de paisaje, pues lo conciben únicamente como medio natural en el que no se aprecian los elementos antrópicos resultantes de la acción humana en el ecosistema.

\section{Conclusiones}

Actualmente podemos encontrar una amplia diversidad de investigaciones acerca del estudio del paisaje en Educación Primaria, de la importancia que se le otorga en la legislación y de las carencias en su proceso de enseñanza y aprendizaje.

En la mayoría de los casos, a pesar de ser un tema innovador y motivador, no recibe el tratamiento que merece y se le da un enfoque tradicional, similar a lo que aprendieron generaciones anteriores. Ahora bien, la preocupación de las sociedades contemporáneas por el paisaje se ha manifestado en la importancia de su tratamiento en el ámbito educativo, como ha puesto de manifiesto el Convenio Europeo del Paisaje. 
Figura 5. Representación del paisaje natural en $5 .^{\circ}$ de Educación Primaria

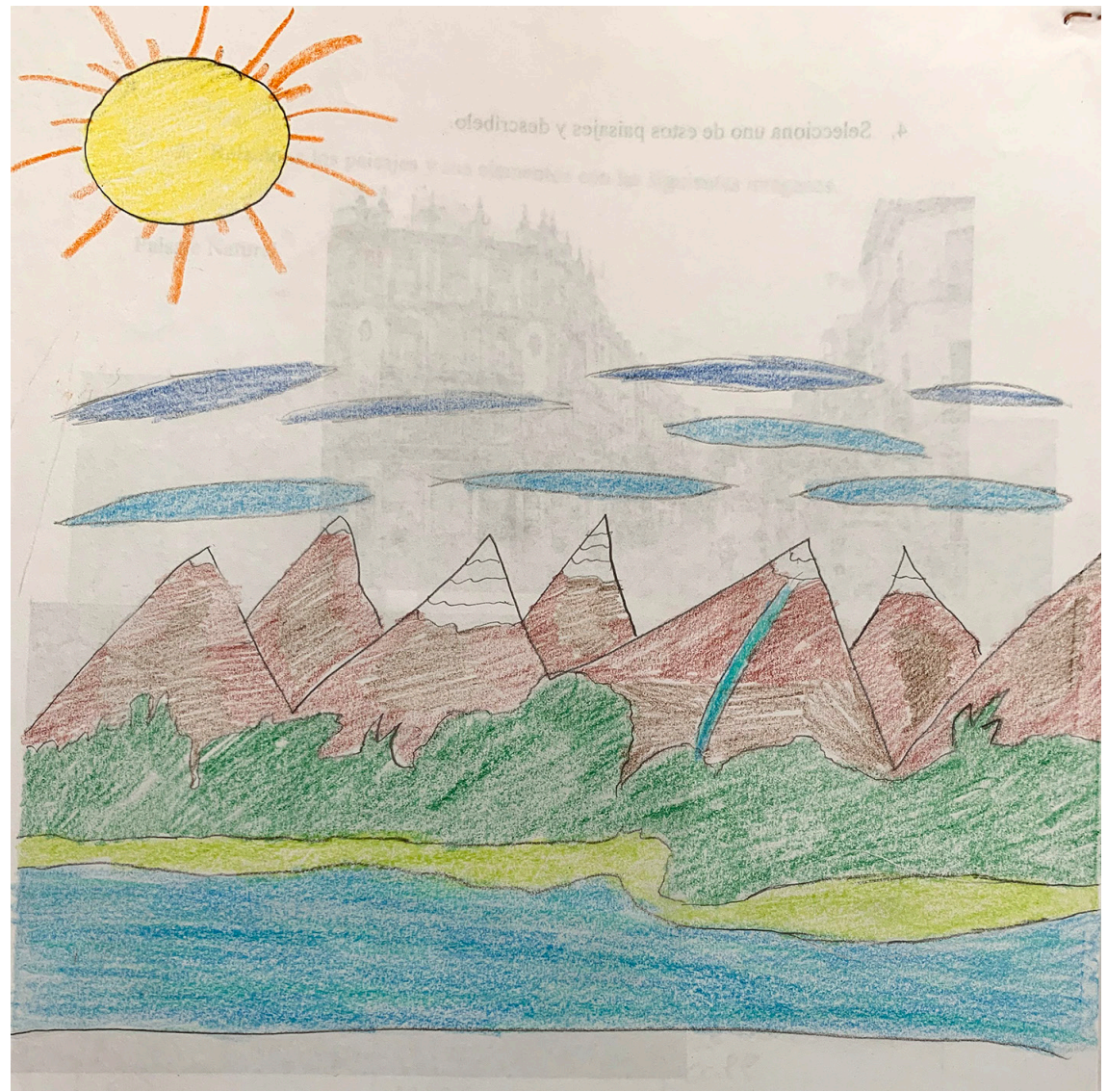

Fuente: elaborado por el alumnado participante en el estudio.

Es cierto que en tan solo unos años se han producido avances notables en su enseñanza y aprendizaje, debido en parte a la gran cantidad de innovaciones docentes que han surgido y a la integración de las nuevas tecnologías de la información geográfica (TIG), pero todavía no se han conseguido las expectativas de la ciencia geográfica en el ámbito de la didáctica.

Dicho concepto puede ser usado como un medio conductor que presenta beneficios didácticos, gracias a su carácter motivador, realista, globalizado y estimulador que permite el desarrollo de actitudes y la implicación en la acción (Otero, 2000).

Con esta investigación, pretendíamos conocer las nociones fundamentales que presenta el alumnado de Educación Primaria sobre el paisaje (a través de sus representaciones gráficas). Como se ha puesto de manifiesto, en los primeros cursos, el alumnado de Educación Primaria es capaz de represen- 
tar cualquier tipo de paisaje, sobre todo los humanizados, que están más próximos a su realidad cotidiana. En cambio, conforme vamos avanzando en la etapa, se va imponiendo una representación del paisaje natural, en el que los aspectos humanos no aparecen o son secundarios. Este hecho se relaciona directamente con lo que establece el currículo oficial: preponderancia del paisaje natural y de los aspectos físicos del medio en Educación Primaria (Martínez et al., 2018), y consecuentemente en la mayor parte de las propuestas didácticas que aparecen en los manuales escolares de Ciencias Sociales (Martínez y Arrebola, 2016). Es por ello que se precisa un cambio legislativo que dé al estudio del paisaje en su globalidad la importancia que merece, partiendo de los paisajes próximos y cotidianos, urbanos y rurales, que son, a fin de cuentas, los espacios donde se desarrollarán como futuros ciudadanos los alumnos de Educación Primaria.

Así mismo, no solo hay que poner de relieve el inadecuado tratamiento curricular, sino que también es preciso incidir en la formación docente, pues son los maestros los que deben conocer el tema y reconocer el gran valor educativo que tiene el paisaje en la enseñanza del espacio geográfico y otorgarle un lugar significativo en las Ciencias Sociales y Ciencias Naturales en la escuela.

García (2014) reitera que se necesita un nuevo enfoque que permita integrar todos los elementos y hechos geográficos, con la finalidad de abordar los problemas latentes en cada paisaje y emprender una mirada renovada que nos conduzca a la representación óptima de la realidad. Un modo sería la aplicación de una metodología basada en el análisis y la interpretación de la realidad más cercana (a través de la contemplación y la descodificación de la información contenida en la imagen visual que tenemos del paisaje), con la idea de descubrir «la riqueza de la diversidad geográfica y cultural para aprender a valorarla y cuidarla» (Orden del 17 de marzo de 2015). Estas estrategias didácticas velarán por el desarrollo de habilidades y capacidades necesarias para educar en una "mirada paisajística» en la que se identifiquen, describan y localicen los diferentes elementos de los paisajes como sistemas complejos, para tomar conciencia de la influencia humana en el medio y sus consecuencias.

\section{Referencias bibliográficas}

ANTrop, Marc (2000). «Background Concepts for Integrated Landscape Analysis». Agriculture, Ecosystems and Environment, 77 (1), 17-28. <https://doi.org/10.1016/S0167-8809(99)00089-4>

- (2006). "Sustainable Landscapes: Contradiction, Fiction or Utopia?». Landscape and Urban Planning, 75 (3-4), 187-197. <https://doi.org/10.1016/j.landurbplan.2005.02.014>

ArnheIm, Rudolf (1954). Art and Visual Perception. Berkeley and Los Angeles: University of California Press.

BAJO, María Jesús (2001). «El paisaje en el currículum de educación primaria, dentro del área de conocimiento del medio natural, social y cultural». Revista de Pedagogía de la Universidad de Salamanca, 13, 51-61. 
BARRAZA, Laura (1999). "Children's Drawings about the Environment». Environmental Education Research, 5 (1), 49-66. <https://doi.org/10.1080/1350462990050103>

BATLlORI, Roser y SERRA, Joan Maria (2017). «D’ensenyar geografia a través del paisatge a educar en paisatge». Documents d'Anàlisi Geogràfica, 63 (3), 617-630. <https://doi.org/10.5565/rev/dag.485>

BUSQUETS, Jaume (1996). «La lectura visual del paisaje: Bases para una metodología». Íber, 9, 53-59.

- (2010). «Educación en paisaje: Una oportunidad para la escuela». Íber, 65, 7-16.

- (2011). «La importància de l'educació en paisatge». En: NoguÉ, J. et al. (eds.). Paisatge i educació, 60-88. Olot: Observatori del Paisatge.

BusQueTs, Lluís (1977). Para leer la imagen. Madrid: Publicaciones ICCE.

CASAS, María y ERNETA, Luis (2015). «El paisaje en la Educación Secundaria Obligatoria. Una oportunidad educativa en el cambio curricular LOE-LOMCE». Didáctica Geográfica, 16, 45-71.

CASAS, María; Puig, Jordi y ERneTA, Luis (2017). «El paisaje en el contexto curricular de la LOMCE: una oportunidad educativa, ¿aprovechada o desaprovechada?». Didáctica Geográfica, 18, 39-68.

Consejo de Europa (2000). Convenio Europeo del Paisaje. Florencia.

Costa, Joan y Moles, Abraham (1991). Imagen didáctica. Barcelona: CEAC.

Creswell, John y Plano-Clark, Vicki (2007). Designing and Conducting Mixed Methods Research. Thousand Oaks: Sage.

Dove, Jane Elizabeth; EvereTt, L. A. y Preece, Peter (1999). «Exploring a Hydrological Concept through Children's Drawings». International Journal of Science Education, 21 (5), 485-497.

<https://doi.org/10.1080/095006999290534>

EHRLÉN, Karin (2009). «Drawings as Representations of Children's Conceptions». International Journal of Science Education, 31 (1), 41-57. <https://doi.org/10.1080/09500690701630455>

GARCÍA, Alfonso (2014). «El pensamiento crítico en el análisis e interpretación de las representaciones sociales del paisaje». En: MARTínez MEDINA, Ramón y TONDA MONLlOR, Emilia María (eds.). Nuevas perspectivas conceptuales y metodológicas para la educación geográfica, 93-108. Murcia: AGE.

Hermann, Dan (1996). «Developing a Spatial Perspective: Using the Local Landscape to Teach Students to Think Geographically». Journal of Geography, 95 (4), $162-167$. <https://doi.org/10.1080/00221349608978716>

Kalvaitis, Darius y MONHARDT, Rebeca (2012). "The Architecture of Children's Relationships with Nature: A Phenomenographic Investigation Seen through Drawings and Written Narratives of Elementary Students». Environmental Education Research, 18 (2), 209-227. <https://doi.org/10.1080/13504622.2011.598227>

KÄrkKÄInen, Sirpa; KeInonen, Tuula; KukKonen, Jari; Juntunen, Seija y RatiNEN, Ilkka (2017). «The effects of socio-scientific issue based inquiry learning on pupils' representations of landscape». Environmental Education Research, 23 (8), 1.072-1.087. <https://doi.org/10.1080/13504622.2016.1177711>

KELly, Donna Darling (2004). Uncovering de History of Children's Drawing and Art. Westport: Praeger Publishers. 
Lambert, David y Morgan, John (2010). Teaching Geography 11-18: A Conceptual Approach. Nueva York: Open University.

LebaZA, Samuel; Zarhbouchb, Benaissa y Picardc, Delphine (en prensa). "Conceptions naïves de la pollution chez les enfants de 7 à 12 ans: une étude de leurs dessins». Psychologie Française. Accesible en línea, 22 de marzo de 2018. <https://doi.org/10.1016/j.psfr.2018.01.004>

LICERAS, Ángel (2003). Observar e interpretar el paisaje: Estrategias didácticas. Granada: Grupo Editorial Universitario.

- (2013). «Didáctica del Paisaje: Lo que es, lo que representa, cómo se vive». Íber, 74, 85-93.

Loughland, Tony; Reid, Ana y Petocz, Peter (2002). «Young People’s Conceptions of Environment: A Phenomenographic Analysis». Environmental Education Research, 8 (2), 187-197. <https://doi.org/10.1080/13504620220128248>

LOWENFELD, Viktor (1947). Creative and mental growth. Nueva York: Macmillan.

- (1958). El niño y su arte. Buenos Aires: Kapelusz.

LOWENFELD, Viktor y LAMBERT, W. (1980). Desarrollo de la capacidad creadora. Buenos Aires: Kapelusz.

Martínez, Ramón y Arrebola, José Carlos (2016). "La enseñanza del paisaje en España. Una mirada a través de los manuales escolares de Ciencias Sociales». Revista Contexto \& Educação, 31 (99), 9-33. <https://doi.org/10.21527/2179-1309.2016.99.9-33>

Martínez, Ramón y Ávila, Covadonga (2014). «El paisaje en los libros de texto de Conocimiento del Medio en Educación Primaria». En: Martínez Medina, Ramón y TONDA MONLlOR, Emilia María (eds.). Nuevas perspectivas conceptuales y metodológicas para la educación geográfica, 465-478. Murcia: AGE.

MARTíneZ, Ramón y GARCÍA-MorIS, Roberto (2014). «El concepto paisaje en los curricula de Educación Infantil de las comunidades autónomas españolas». En: MARTíNEZ Medina, Ramón y TONDA Monllor, Emilia María (eds.). Nuevas perspectivas conceptuales y metodológicas para la educación geográfica, 479-496. Murcia: AGE.

MarTíneZ, Ramón; LópeZ, José Antonio; Medina, Silvia y García-Moris, Roberto (2018). «El paisaje natural y cultural en el nuevo currículo de Educación Primaria (LOMCE)». En: CADERÓN RoCA, Belén (coord.). Valores e identidad de los paisajes culturales: Instrumentos para el conocimiento y difusión de una nueva categoría patrimonial, 349-370. Granada: Universidad de Granada.

Medley, Kimberly E. y Gramlich-Kaufman, Lori M. (2001). "A Landscape Guide in Environmental Education». Journal of Geography, 100 (2), 69-77. <https://doi.org/10.1080/00221340108978419>

MELA, Alfredo (1994). La città come sistema de comunicazioni sociali. Milán: Franco Angeli.

Nogué, Joan; Puigbert, Laura; Bretcha, Gema y Losantos, Àgata (2011). Paisatge i educació. Olot: Observatori del Paisatge de Catalunya.

«Orden por la que se desarrolla el currículo correspondiente a la Educación Primaria en Andalucía» (Orden de 17 de marzo de 2015). Boletín de la Junta de Andalucía, n. ${ }^{\circ}$ 60, 27 de marzo.

OTERo, Isabel (2000). «Paisaje y educación ambiental». Observatorio Medioambiental, 3, 35-50.

PuyUelo, Miguel y Rondal, Jean-Adolphe (2003). Manual de desarrollo y alteraciones del lenguaje. Aspectos evolutivos y patología en el niño y el adulto. Barcelona: Masson. 
Real Decreto 126/2014, de 28 de febrero, por el que se establece el currículo básico de Educación Primaria. Boletín Oficial del Estado, n. ${ }^{\circ}$ 52, 2014, 1 de marzo.

RiCKINSON, Marc (2010). "Learners and Learning in Environmental Education: A Critical Review of the Evidence». Environmental Education Research, 7 (3), 207-320. <https://doi.org/10.1080/13504620120065230>

ScotT, Alister; Carter, Claudia; Brown, Katrina y White, Vicki (2009). «Seeing is Not Everything: Exploring the Landscape Experiences of Different Publics». Landscape Research, 34 (4), 397-424. <https://doi.org/10.1080/01426390903009289>

SiAmA, Ioanna; TeRKenlo, Theano y KlONARI, Aikaterini (2018). «Building a landscape educational program for the needs of Greek preschool and primary-school children: a methodological approach». European Journal of Geography, 9 (1), 80-90.

Wallon, Philippe; Cambier, Anne y Engelhart, Dominique (1992). El dibujo del niño. Madrid: Siglo Veintiuno de España Editores.

WidlÖCHER, Daniel (1982). Los dibujos de los niños. Barcelona: Herder.

WiśNIEWSKA, Agnieszka (2017). "Drawings by children aged 3-12 in the context of new media». Cognitive Science - New Media - Education, 2 (1), 129-139. <http://dx.doi.org/10.12775/CSNME.2017.008> 
